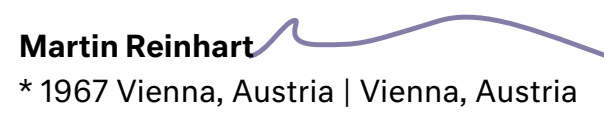

Martin Reinhart is a filmmaker, historian and inventor. He studied at the University of Applied Arts Vienna. He is a trained film technician and his company Indiecam has pioneered digital moviemaking since the 2000s. Together with Thomas Tode and Manu Luksch, he co-directed the documentary Dreams Rewired (2015) that won the prize for best director at the Moscow International Documentary Film Festival. In 1992 Martin developed $t x$-transform, a film technique which made it possible to restructure space and time in a way that challenges visual recognition of movement. He has continued to refine this process ever since. Consequently, in 2019, together with Virgil Widrich they made the $360^{\circ}$ film $t x$-reverse which set new industry standards for immersive engagement.

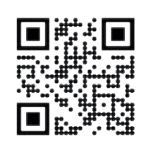


1 Gerda Haßler and Cordula Neis (2009), Lexikon sprachtheoretischer Grundbegriffe des 17. und 18. Jahrhunderts, (Berlin: De Gruyter), 544-46.

2 Haßler and Neis, Lexikon sprachtheoretischer Grundbegriffe, 514 .
In Judeo-Christian mythology, there are at least two narratives that revolve around the hazards inherent in knowledge. The first of these concerns Eve, who is incited by the serpent to taste from the fruit of the tree of knowledge and thereby provokes the expulsion from paradise. The second, which is more central to my reflections, deals with the concept of an original language and the profound disorder that came upon humankind when it was deprived of the ability to understand it.

Legions of scholars who tried to interpret this biblical story could never agree whether the original language was the language of God or the one genuinely used by Adam to name all things. This was also the subject of century-long debates as to whether remnants of this language had survived in Hebrew, the language of the chosen people, or in Latin, the official language of the Christian church.' The essential point of agreement, however, was the alleged fact that in this original language there was no difference between an object and its name, and it therefore represented a self-consistent and perfect system of meaning through which the genius of God's creation would be reflected. In this understanding all natural phenomena and all their names were connected by a dense and God-given web of similarities. The true form of a thing could thus be recognised by its true name-just as each thing was originally inscribed with its true name. This divine symmetry of words and things was lost to the human as punishment for building the sacrilegious Tower of Babylon, and was followed by centuries of scholastic discourse and argument in an effort to restore what had been lost.

Until the early Middle Ages, the Babylonian confusion of language was mainly considered to be a moral allegory and the just penalty for the hubris of defying God. In this interpretation, all humans spoke the same language which, in the eyes of God, gave them too much power. Unlike the Noachian flood, God countered this case of human overreaching with a more strategic punishment: ending their unity and confounding people by making the common language unintelligible. In the 13th century, a change in this scholastic interpretation became apparent. ${ }^{2}$ Babel would have resulted less in a confusion of languages and more in a rearrangement of principles of order and hierarchies. Since then the tendency of the preferred narrative has been seen as a

\footnotetext{
absurdity [ab's3:diti]

to give the void its colours. a question of not explaining and not solving, but experiencing and describing. as chantal faust recommends: to call present reality into question. exemplified by the dadaists, the embodiment of absurdity continues to be called upon by artists and writers as a response to global anxiety and indolence.
} 
coherent explanation for the origin of different languages,

a view that eventually led to the first nation-based language

tendencies and early dialectologia such as De Vulgari Eloquenti by

Dante Alighieri. ${ }^{3}$ But it was commenly held that all post-Babylonian

languages would remain unable represent adequately the true nature

of the world. The belief that the hidden essence of things could be

revealed by scholastic discourse slowly lost its significance and the ambition to decode the spiritual unity between the word and the world increasingly shifted towards the obscure fields of alchemy, cabbalistic and Lullist mysticism. Then, in the Renaissance, the unitary concepts, which urged a reversal of Babel by reconstructing the original language collided with the urge to create a modern scientific language and caused an irreconcilable split.

\section{The book of nature}

In 1543 two important works were published in the same year. In time, these were to provide a fundamental impetus to modern sciences: De revolutionibus orbium coelestim by Polish astronomer Nicolaus Copernicus and De humani corporis fabricaby Flemish anatomist and physician Andreas Vesalius. ${ }^{4}$ By praising the empirical approach and introducing an inherent lexical system, both books changed the position of how human beings related to God. In this respect, Vesalius's work was the more radical since he made a single-handed attempt at translating the corporeality of a living human body into a quasi-hermeneutical system. The significant point here is that Vesalius peremptorily broke with scholastic tradition and spoke of a 'Book of Nature' in which divine order is expressed. In his view a thing is not explained by its relationship to the cosmic whole or by the means of an intellectual discourse, but carries the seed of its meaning within itself. In order to be able to read the language of nature, everything must first be named anew and then described representatively in every detail. This distinguishing of meanings requires a specific form of observation that reveals connections which otherwise would remain hidden. In this respect, the term 'empirical' is not entirely appropriate for Vesalius's method, since it is less about an unprejudiced investigation and more of a quest for coherent principles or models that are capable of costituting an emergent ideal. 
Fig. 1: Cover illustration from the second book of Andreas Vesalius On the Fabric of the Human Body in Seven Books. Woodcut by Jan Stephan van Calcar, 1543. An anatomist's instruments to explore the truth beneath the surface laid out on a table. 
The means of uncovering this are, on the one hand, connected to the various techniques of seeing-especially with the aid of instruments: scalpels, microscopes, telescopes, etc.-and, on the other hand, the use of a differentiated and unequivocal language which clearly separates specific instances. The demands and aspirations of this programme meet both metaphorically and practically in the activity of anatomists. They dissect the body, resolving it into its component parts according to the grammar of its physiological and morphological context, naming its individual elements. Language replaces the causalities lost in the process and once again postulates a whole even when only fragments remain. As a result, a discourse of exclusion generates a model of reality in which cosmology is replaced by a notion of the ideal. In the case of the Fabrica, a universal model was thus constituted from within the individual body, though it had to be first distilled from a variety of misleading meanings and forms. Illness and deformity were no longer stigmas imposed by a punitive divine authority, nor were they reflections of cosmic disharmony; instead they are aberrations-deviations from a distinct set of rules. The most interesting features in this context are the lavish 663 large folio and 300 smaller illustrations of the Fabrica and their close relation to the descriptive text. In contrast with medieval anatomical diagrams, which were all textual schemata, this new kind of illustration signified a fundamental change in the methods of creating and communicating scientific knowledge.

In keeping with the conceptual basis of Vesalius's own methods of research and teaching, the illustrations had to replace the dissected corpse and transform it into the single, delicate, human body through which nature spoke truth from within. The image was no longer the symbolic carrier of meaning; rather, the text spoke through the picture about the body animate. The skill of the engraver in this context was not only to meet the requirements of the knowledge formulated in the description but to create the impression of sentient life, too. While this form of representation may be derived from the postulated premise that anatomy should also make statements about the physiology of the human body, it also serves to obscure the fact that the insights about life have been won from the corpses of executed criminals. ${ }^{5}$
5 Cf Martin Reinhart (1994), Invia Virtuti Nulla Est ViaThatkraft kennt kein Hinderniss. Idealisierung und Marginalisierung in den Darstellungen von 'De Humanis corporis fabrica' des Andreas Vesalius. Betrachtungen zur Anatomie als medizinische Praxis im 16. Jahrhundert, unpublished thesis, (Vienna: University of Applied Arts Vienna). 
Leaving aside any of the technical, legal or practical obstacles that Vesalius had to overcome in order to produce and publish his magnum opus, it is safe to say that the Fabrica can be seen as an early and prototypical example of a modern knowledge system, which can be understand as a set of interconnected ontologies with permeable borders. In other words it is, and proposes, a specific kind of organisation rooted in the traditional fields of logic, hermeneutic and semiotics but nevertheless still incorporates some of the fibrous flesh from which it originates.

In this context, therefore, a knowledge system appears to be more like a living organism that reacts and shifts with interaction. Here the fundamental difference to reductionist or idealised forms of data organisation is that its certainty only exists relative to, and dependent on, a dynamically changing system (in Vesalius's case: the body). On the other hand, such a system always needs a moderator, or translator, because knowledge can only rarely be a factual value in itself, since it always interacts with adjoining fields and-like Schroedinger's cat-it only exists at the exact moment it is consulted.

\section{Conquering worlds of plenty}

Apart from Vesalius's description of the human body, the Renaissance also drove at least two other aspects of the human quest for knowledge. One of these was the close reading of classic sources and the growth in distribution of new knowledge via the letterpress. Another was Europe's eagerness to conquer new territories in order to colonise and exploit them. In both cases the understanding and relevancy of text and images evolved in radical ways. Taking possession of the world soon proved to be a worthwhile undertaking for the great powers of Europe, which fought centurylong battles for supremacy over colonial territories. Missionaries, traders, settlers and scientists came in close conjunction with the occupying powers. They soon acquired knowledge of the properties of the local resources and searched for suitable methods to report back on their newly gained intelligence. This produced maps, drawings and descriptions along with living and conserved specimens, which were shipped home by the millions. While the idea here was clearly to document as much as humanly possible and not simply to find the one precious needle in the haystack, there was also a drive to trace things back to their origins. This was nothing less 
than the optimisation of looting by metrics. This, of course, required documentation procedures to take on yet another character, one that was precise enough to describe the appearances of a subject in detail and to provide a system of categories indicating its position within a group that shared similar properties. These collections were refined over centuries and, as the blank spots were gradually resolved, they became the foundation on which modern sciences such as geology, biology and chemistry were built.

Elsewhere, the rediscovery of Greek, Latin and Hebrew texts from ancient times provided a drastic demonstration of how knowledge could be lost, as well as the methods by which it could partially be recovered even after more than a thousand years. The strategy of the mediaeval period was to translate important manuscripts into hand-written Latin. Organisation was normally alphabetical and, since monastic libraries that were the contemporary repositories were operated by different orders of the Catholic Church and only loosely interconnected, there was no central or comprehensive listing of all the documents and books kept there.

Due to the economic and cultural strengthening of the European cities in the 14th century, universities re-emerged and began to build up their libraries, giving substance to and advancing the basis of their teaching and research with both contemporary knowledge and that gained from the ancient world. The spirit of the Renaissance saw these institutions systematically searching for ancient documents or copies that had survived in European archives. At the same time, a significant number of original texts considered lost were re-translated from Arabic sources.

For the first time in modern history human thought manifested in text had re-emerged after centuries in oblivion. These were seen as essential resources capable of contributing to what was now understood to be an evolving humanity. However, those texts were also a warning that cultural achievements would not necessarily endure. So multiplying and distributing knowledge through printed books was regarded as a valid strategy to protect knowledge, but also as a way to inscribe one's own position into canonical knowledge systems. This new awareness was embodied inter alia by universal polymaths who were able to assemble the knowledge of the time, and by printers who were in many cases highly educated intellectuals. 
6 Conrad Gessner (1545), Bibliotheca Universalis, sive Catalogus omnium Scriptoum locupletissimus, in tribus linguis, Latina, Græca, \& Hebraica; extantium \& non extantium, veterum et recentiorum in hunc usque diem ... publicatorum et in Bibliothecis latentium (Zurich: Christophorum Froschouerum).

\section{Gabriel Naudé (1963 [1627]), Advis pour dresser une bibliothéque (Leipzig: VEB Edition Leipzig) and Louis Jacob (1645), Traicté des plus belles biblio- thèques publiques et particulières qui ont été et qui sont à présent dans le monde (Paris: Rolet le Duc).}

The result was that Renaissance libraries were filled with such a wealth of books and manuscripts that librarians were needed to plan and organize this accumulated knowledge. Here is where we find the first library catalogues emerging. By publishing his Bibliotheca universalis in 1545, just two years after the publication of the Fabrica, the Swiss scholar Conrad Gessner made one of the early attempts to create a comprehensive listing of all the books from the first century of printing. ${ }^{6}$ The extensive work aspired to be a complete survey of all known writings in Latin, Greek and Hebrew and included approximately three thousand authors as well as a subject index.

\section{It is order that gives light to memory}

With printed books, the availability and distribution of knowledge soon increased exponentially. A Baroque library such as the one still existing in the Admont Abbey in Styria (Austria) was built to hold some 70,000 copies in its central book hall. An even more impressive example is Étienne-Louis Boullée's neoclassical project for the Bibliothèque royale in Paris with a reading room about a hundred metres long and thirty metres wide. This would have been the largest in Europe holding more than 300,000 volumes. One beautiful feature of these two libraries dating from the 1780s is that all the books were organised in shelves within the same hall, assembling in plain sight all available ken of its time. Although one theoretically still could physically reach every single copy, this size of collection already demanded more sophisticated forms of organisation than a simple alphabetical order or a division into subjects. It becomes understandable when, in and around 1630, first treatises were published reflecting the organisation and improvement of libraries. One of them was Gabriel Naudés's widely circulated Advis pour dresser une bibliothéque and Louis Jacob's Traité des plus belles bibliothéques-not to mention the even greater number of historiae literariae and catalogues of public and private libraries that also started to circulate at this time. 7 In this very influential work on library science, French librarian and scholar Gabriel Naudé promoted the idea of the universal library, which was to contain all human knowledge regardless of provenance or subject. ${ }^{8}$

\footnotetext{
8 In his Advis, Naudé writes: "And therefore I shall ever think it extremely necessary, to collect for this purpose all sorts of books, (under such precautions, yet,
}

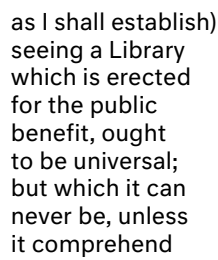
all the principal authors, that have written upon the great diversity of particular subjects, and chiefly upon all the arts and sciences; [...] For certainly there

is nothing which renders a Library more recommendable, then when every man finds in it that which he is in search of

...” Naudé (1963

[1627]), 19-20. 
At about the same time English philosopher and science theorist Francis Bacon claimed that any classification of knowledge should be universal and the access to educational resources must be provided for the public. To organise all types of knowledge Bacon proposed three general groups-history, poetry, and philosophy-and he also introduced the three ways in which this knowledge could be processed, namely by memory, imagination, and reason. ${ }^{9}$ Among the next generation of librarians, German philosopher Gottfried Wilhelm Leibniz was without doubt one of the most visionary and innovative. In the late seventeenth century he continued to promote the notion of the universal library, actively trying to implement it during his service as a librarian for the Hanoverian court and later for the Bibliotheca Augusta at Wolfenbuettel. In both cases he had a constant struggle with a lack of funds, intrigues and ignorance and never actually was able to realize his ambitious plans to their full extent. The extant correspondence with his employers and his own reflections convey a detailed picture of his struggle for adequate acquisition budgets but also of his distance from the traditional figure of a court librarian. ${ }^{10}$

Unlike his colleagues and precursors, Leibniz's approach did not end with the idea of gathering, storing and cataloguing all available books. Instead, he envisioned a universal concept of knowledge based on the principles of reason. In his writings, Leibniz compares the state of human knowledge to a storehouse that contains a multitude of precious goods but lacks both order and a proper inventory.

"Humankind therefore wanders with difficulty and confusion in the dark, without guidance or precise direction, without a possible object and even without knowing its present state. Real advancement, therefore, necessarily requires a filum Ariadnaeum to serve as a guide through centuries of reflection, observation, and discoveries made by our ancestors-a heritage that is at risk of being erased from our memory."11

Another aspect that arose from a similar mindset is that of completeness. This was manifest not only in the universal library but also in the concept of the encyclopaedia which were, to Leibniz's mind, almost synonymous. As he wrote to Duke Johann Friedrich in 1679: "It is necessary for a library to be an encyclopaedia."12
9 Francis Bacon (2017 [1620]), The Novum Organum, (Scotts Valley, US: Create Space).

10

Cf Margherita Palumbo (2018), "Leibniz as Librarian," in Maria Rosa Antognazza, The Oxford Handbook of Leibniz, (Oxford: Oxford University Press), 609-22.
11 Cf Leibniz as quoted in Palumbo (2018), Ibid, 621.
12 Neue Deutsche Biographie [NDB] (1953), Historische Kommission bei der Bayerischen Akademie der Wissenschaften ( $E d$.$) ,$ (Berlin: Duncker und Humblot), Vol. 10, 478.

Fig. 2: Interior view of the new hall planned for the extension of the King's library in Paris. Ink drawing with sepia wash by Étienne-Louis Boullée, 1784 (Bibliothèque nationale de France). The exponential growth of human knowledge is represented as the geometrical vanishing point of virtually endless bookshelves. 


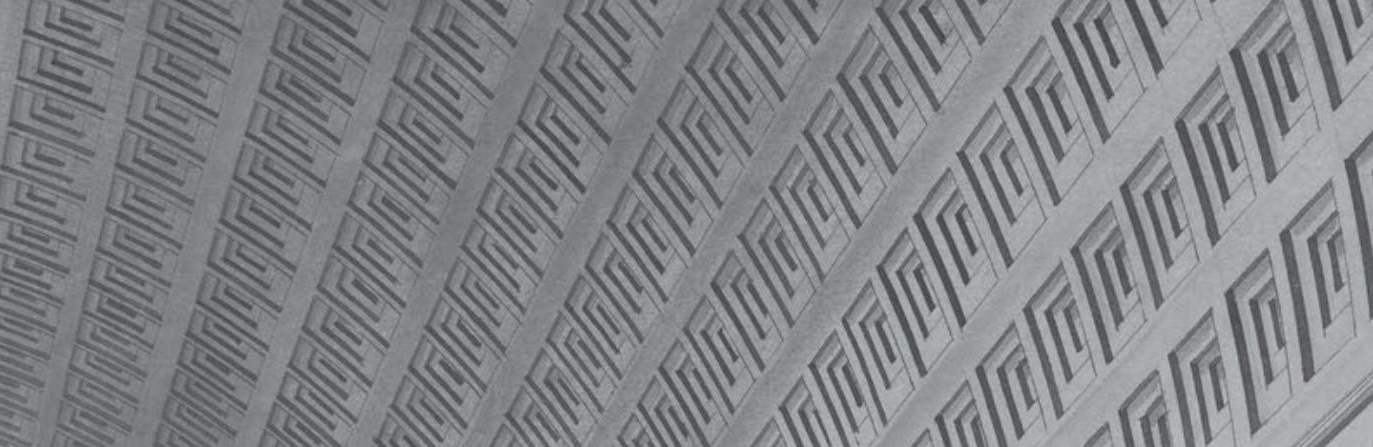

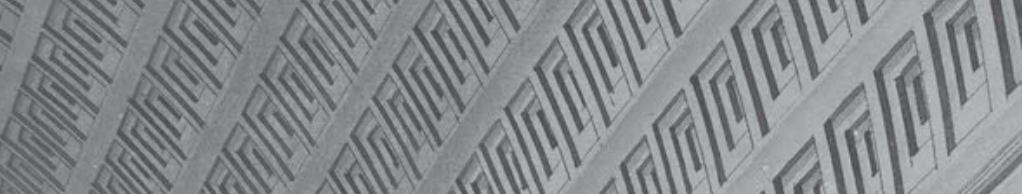

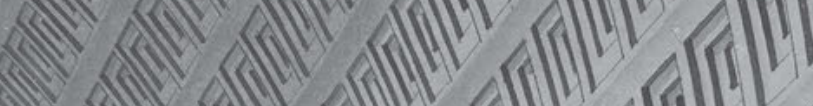

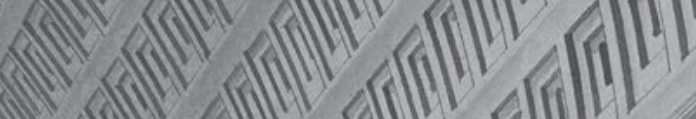

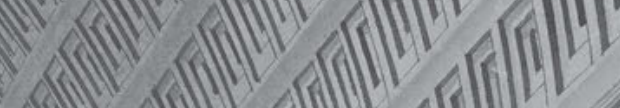
smi sañ ay añ arm ân

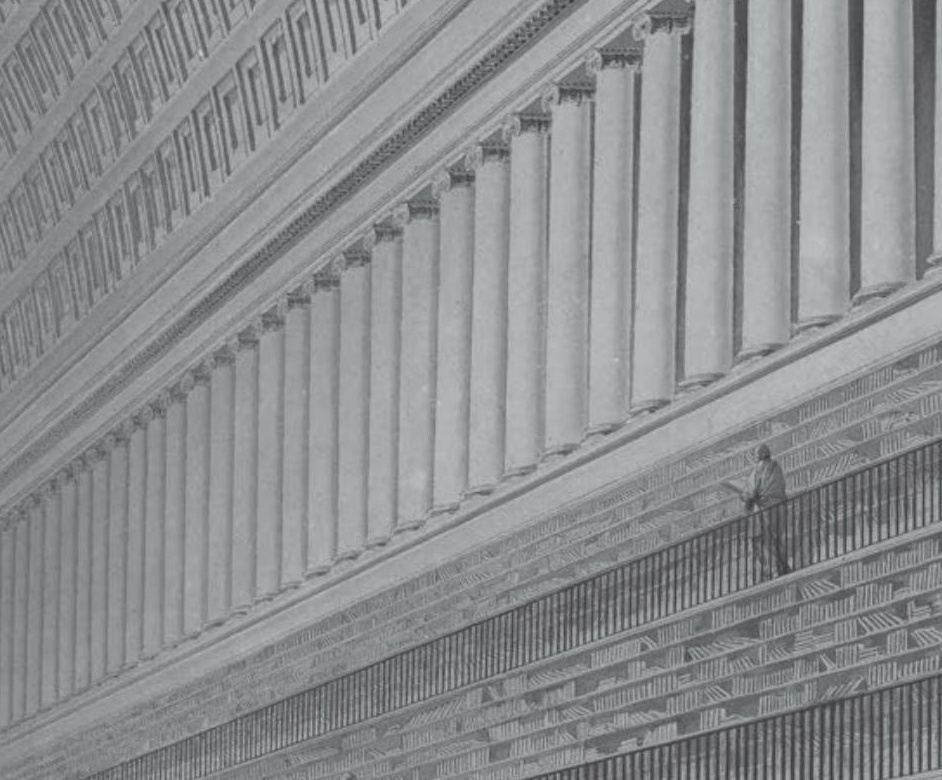

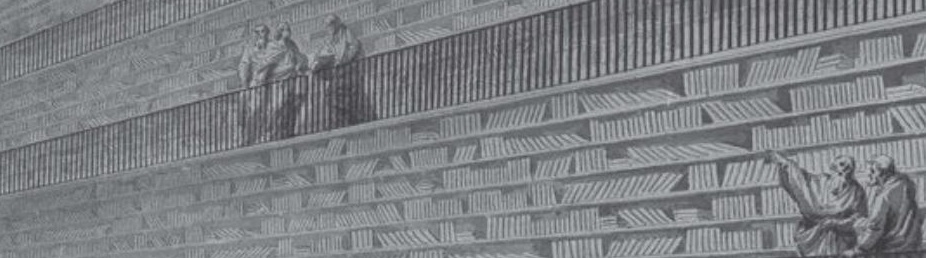

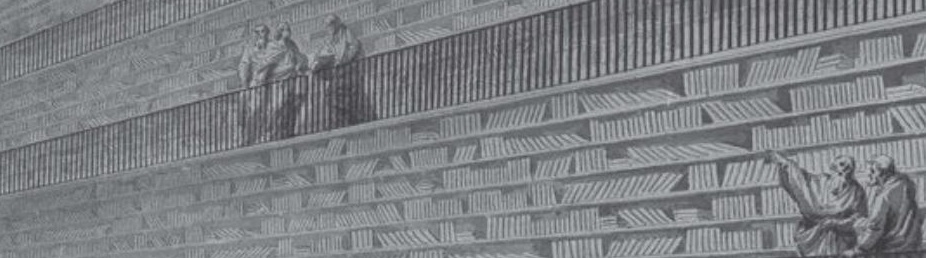

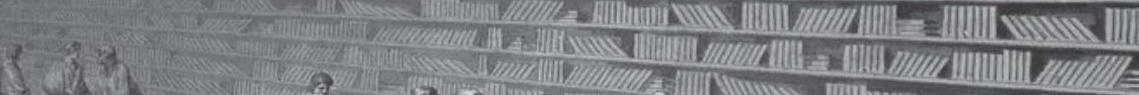
mix $2-193$

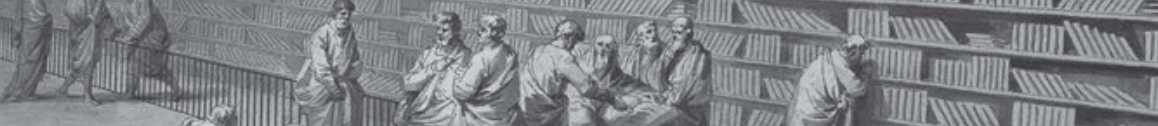
(2) $x<$ aiv

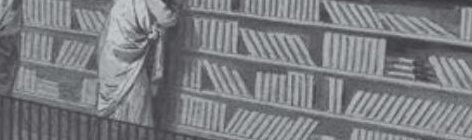


13 Cf Letter from Leibniz to Fredrich Wilhelm von Görtz, January 261706 (A I, 25 N, 236: $532)$, as quoted in Palumbo, "Leibniz as Librarian,” 615, fn 15 .

14 Cf G.W. Leibniz (1989 [1666]), "Dissertatio de Arte (Dissertation on the Art of

Combinations)," in Philosophical Papers and Letters, edited by Leroy Loemker, (Berlin: Springer), 73-84. It should be noted that there remains strong debate as to whether Leibniz was the original inventor of the binary system. See for example, J. Ares et al (2018), "Who Discovered the Binary System and Arithmetic? Did Leibniz plagiarise Caramuel?" at doi.org/10.1007/ s11948-0179890-6

15 Cf Herbert Breger (2009), Leibniz' binäres Zahlensystem als Grundlage der Computertechnologie, in: Jahrbuch der Akademie der Wissenschaften zu Göttingen, (Berlin: Walter de Gruyter), 385-91.

\section{How to navigate the jungle of all knowledge}

For Leibniz a library never appeared as something static, but rather as "an animal, a living being that necessarily requires constant and adequate alimentation for its survival."13 This analogy might be extended to his entire concept of knowledge since in his view the three foundations of an ideal system of classical knowledge were the establishment of scientific societies and the development of an encyclopaedia of the sciences, coupled with a universal library. In order for all these vessels and sources of knowledge to communicate and condense information into undisputed truth, Leibniz introduced his concept of the characteristica universalis-a universal system of signs capable of representing all objects and ideas as well as the relationships between them.

One question that arose in this context was whether common signs, like letters or numbers, could be flexible enough to describe and formalise the known universe. In order to make this possible, it was believed that one would need to come up with a set of even more abstract signs, which then would allow the translation of everything in existence into one universal language. Leibniz found a solution for this requirement by introducing a binary system which reduced the number of signs to exactly two. ${ }^{14}$ According to him, the symbol 1 denotes the singular unit or the number one, the symbol 0 (nullum) denotes the inability to divide and its lack of existence. Leibniz further argued that if, in accordance with the Pythagorean doctrine, everything is a number, and with the Aristotlean thesis that the essence of things are numbers, then the binary number system, in which all numbers are constructed from 0 and 1 , can only be understood as a symbol of the divine creation: God or absolute oneness creating everything from nothing. ${ }^{15}$

This belief interconnects with the much more comprehensive concept of the universe Leibniz had developed; namely, the theory of the monads, which he described in a letter to French philosopher Nicolas François Rémond (1714) two years prior to his death. According to the metaphysics that he developed, there is one original monad, which is God. All the others are its descendants. Everything is made from these infinitely small units, which can have all kinds of properties as well as the ability to aggregate. They are very much like atoms but are indestructible and, at times, follow their own agenda. 


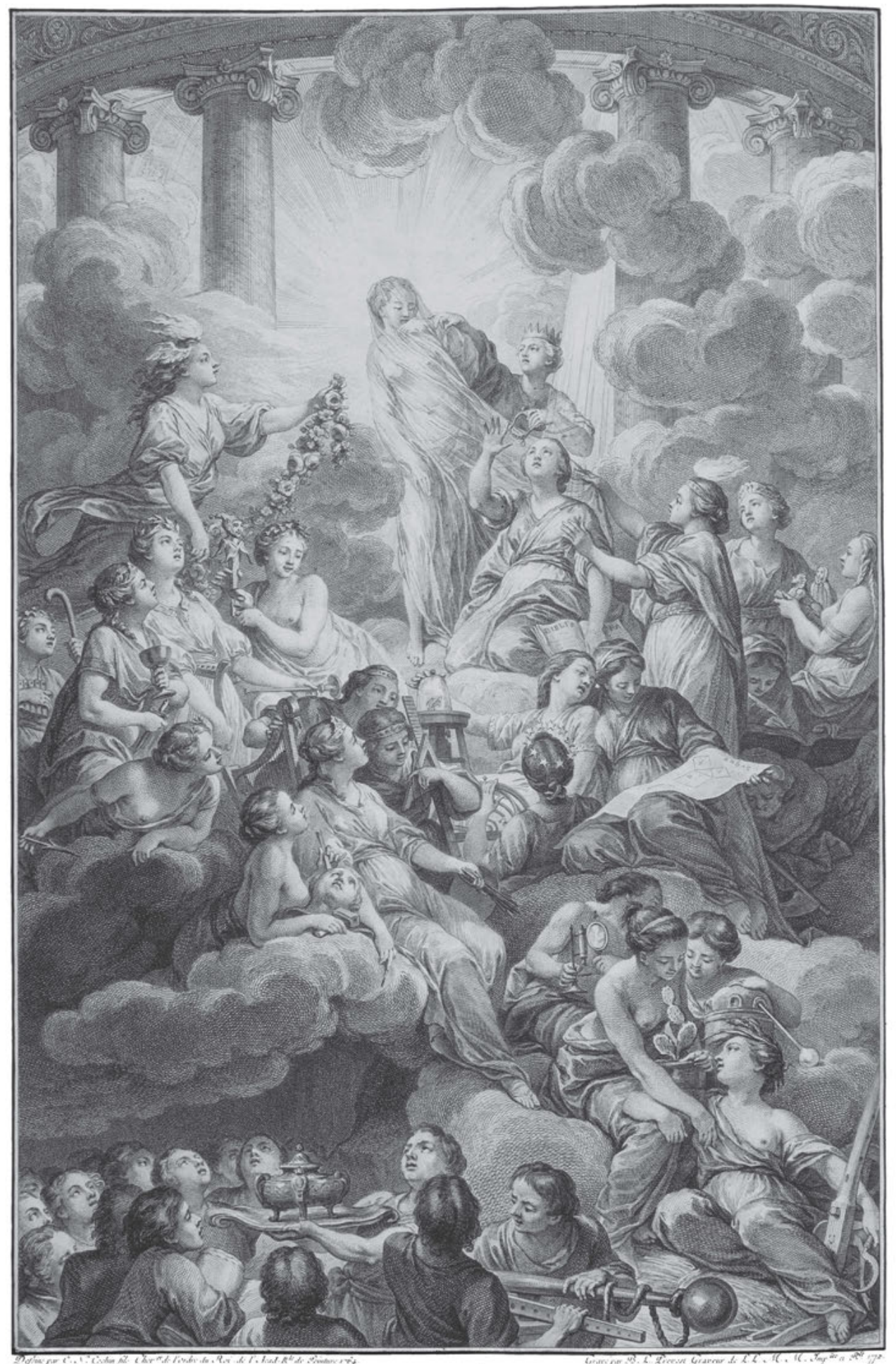

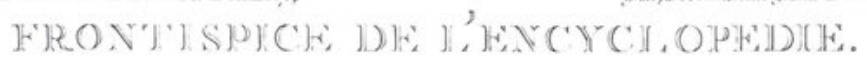


16 Anna Holterhoff, (2009), "Naturwissenschaft versus Religion? Zum Verhältnis von Theologie und Kosmologie im 18. Jahrhundert", as part of TOPOI-The Formation and Transformation of Space and Knowledge in Ancient Civilisations, (Berlin: Freie Universität Berlin and Humboldt-Universität zu Berlin) at www. fu-berlin.de/en/ sites/inu/research/ clusters-alt/topoi/ index.html
As the original monad, only God is able to judge and regulate the degree of harmony in which the world 'is', but as the monads are also able to self-organize, this, for Leibniz explains the fuzzy and confusing reality of the human world. The idea that both monads and binary systems have in common is that anything can be divided over and over again unless a conceptual element is revealed (God or the 0), which in turn serves as the universal building block. And just as all words in a language can be represented by the letters of the alphabet, so the whole world of nature and human thought can be considered in terms of a number of fundamental elements. Leibniz hoped that ultimately the combination of a perspicuous thought language of pure concepts would be combined with formalised processes and methods akin to those used in mathematics and thereby lead to the mechanisation and automation of reason itself.

Without being able to go deeper into Leibniz's achievements and thoughts, one can say at this point that although not all the implications of his visionary projects have proved fruitful, his notion of the mathematisation of knowledge not only inspired subsequent generations but, in the long run, has had a fundamental impact on how we process data today. As the inventor of the first mechanical binary calculating machine, Leibniz is often regarded as essential to the foundation of modern techno-science because his contribution reflects the analytical and generative possibilities of rendering the world computable. However, this retro-logic is misleading since it follows the idea of linear development and excludes the historical context in which his idea was originally conceived.

\section{Turn of an era}

Leibniz and many other scholars and scientists of his time shared the belief that God's creation was based on a set of eternal rules, which God gave to humanity the gift of reason so that eventually the beauty and genius of this divine creation would be comprehended. The combination of these two concepts-the religious belief in God's will and the secular belief in human free will-might seem contradictory to us today. Very likely this misunderstanding might also be a reason why the late 17th century and most of the 18th century have long been regarded as an era of consolidation and elaboration of already existing knowledge, offering little in the way of innovation.16

\footnotetext{
algocracy ['ælgəo'kreızi]
}

the rule by algorithm relying on political, mainly neo-liberalist, positions that are expressed by and help to express a current state of affairs. collective decision making based on functionalist propositions. see the important blog algocracy and the transhuman project, led by john danaher and pip thorton. 
Without wanting to go further into the role of religion, nevertheless it is important to indicate that at that time the scientific understanding of the world was less involved in the idea of utilisation and optimisation and instead had an entirely different concept of progress than that of the following centuries. In fact the turn of the 18th to the 19th century was much more radical in the way that society changed than that of the Middle Ages to the Renaissance. This was simply because change occurred in almost every facet of life and at the same time was compressed into an incomparably shorter period. This fundamental change would soon affect all of Europe-if not the entire planet-in one or another way. It essentially dis-ordered the world and unhinged the structure of society in unseen ways. In this context Karl Marx's famous quote "all that is solid melts into air" is not only true for commodities and capital, but for almost every other certainty humanity had conceived up to this point."

The 18th century ended with a world-shattering and momentous event: the French Revolution, which occurred between 1789 and 1799 . The abolition of the feudal-absolutist corporative state and the propagation and implementation of fundamental values and ideas of the Enlightenment were, as objectives of the French Revolution, among the reasons for far-reaching changes in societies throughout Europe. It also had a decisive influence on the separation of State and Church as well as on the separation of science and religionconnections that were previously undisputed.

Leaving aside the enormous impact the French Revolution had in almost every other field, two interconnected aspects that seem comparatively minor, but which were eventually to become of great importance for the entire 19th century, need to be addressed. The first is the standardisation of units of measurement and the other is the introduction of the metric system-or, to be more precise, of decimal fractions. Neither of these achievements was a contemporary invention nor the direct result of the Revolution, though its radical political programme did make their implementation possible, first in France and then later in many other countries.

Today we are so used to these achievements, it is hard to imagine a world where literally every large town had its own measurements of length and weight-a situation that not only promoted manipulation and fraud, but also hindered scientific exchange and progress.

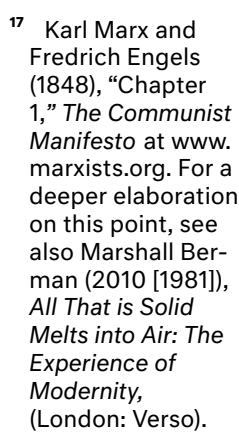

(London: Verso). 
The very same problem that Vesalius solved almost single-handed in the case of medical nomenclature was now a challenge in all other fields of science. An initial step to address this challenge was the standardisation of measurement in order to make results reliable and comparable. The new and universal units of measurement were chosen in such a way that subunits were always decimal multiples and fractions of these universal units. The struggle for this seemingly simple solution took centuries and, as a matter of fact, the process has not yet been completed outside the scientific context. It is very instructive to understand that these important steps towards the rationalisation of knowledge were only taken comparatively late in European history and it is surprising to see the obstacles they had to overcome before finally prevailing. The incredible technological acceleration that started at the end of the 18th century and was at full throttle around 1850, seems deeply interconnected with these profound reforms.

It is not surprising that this rational premise also had a fundamental influence on how the world was viewed from then on. One peculiar paradox in this context concerns the latent opposition encountered from the beginning of the 19th century to the unification and specialisation in the sciences. On one hand, the standardisation of terminology and measurements was pushed in both scientific research and in industry, which was growing explosively. On the other, the exponential growth of knowledge led to an ever-finer differentiation of branches and disciplines. As a result the unitarian concepts of the cosmos increasingly fell apart. While in the 18th century an attempt at a comprehensive and complete description of the world was still conceivable, less than a hundred years later the idea bordered on the delusional.

A good example of this shift is the enterprise of Denis Diderot and Jean-Baptiste le Rond d'Alembert, who worked on their Encyclopédie between 1751 and 1772, attempting nothing less than a comprehensive list of all aspects of human existence. Contemporaries saw the richly illustrated work as ground breaking and it appeared self-evident that with sufficient effort it could be extrapolated into a future of infinite detail. A hundred years later, however, Alexander von Humboldt's attempt to put his life-long research into a coherent compendium failed gloriously. 
His Kosmos was published between 1845 and 1862 in five volumes.18 But by that time it was beginning to dawn on those in the scientific community that the figure of the polymath coupled with the ideal of universal knowledge was outdated and had to give way to a new kind of fragmented specialisation.

\section{The terror of ten}

By the mid 19th century, the industrialisation of letterpress printing brought more books at decreasing prices onto the market, which included scientific treatises, technical books and patents. This data helped the acquisition of up-to-date knowledge that would transcend national borders and in turn would promote worldwide scientific and technical progress. It is therefore not surprising that library systems had to adapt to new demands in managing this flood of new information. In his 1876 paper American entrepreneur Melvil Dewey proposed a faceted library classification system which would eventually become the blueprint-in the Anglo-Saxon world at leastfor the organisation of large bodies of data. ${ }^{19}$

The basic idea of the Dewey Decimal Classification (DDC) was not new at the time and can be traced back to a similar system proposed by Leibniz. ${ }^{20}$ Unlike his prominent predecessor, however, Dewey had no philosophical ambitions; his thinking was strictly business oriented. He was an enthusiastic supporter of the decimal metric system and established the Boston based Metric Bureau in 1876. It was one of the first providers of supplies for libraries in the USA. The company closed in 1881, but Dewey seamlessly continued to do business under another company, the Library Bureau, in Cambridge Massachusetts, which he headed for the next 25 years. ${ }^{21}$ The DDC grew out of the specific demands of physically finding one book among millions of others, a challenge that was substantial for libraries worldwide. Up to the 19th century most library stacks were generally closed to the public and only librarians were allowed to organize and browse the shelves. Normally each book was assigned a permanent shelf position based either on its height, the date of its acquisition or the first letter of the author's name. Of course these characteristics only allowed ineffective forms of organisation, which became more and more inferior with the exponential growth in numbers of books.
18 Alexander von Humboldt, (2015 [1845-1862]), Der Kosmos - Entwurf einer physischen Weltbeschreibung (Cosmos: A Sketch of a Physical Description of the Universe) in 5 volumes, (Stuttgart and Tübingen: J.G. Cotta).

19 Originally published as Melvil Dewey (1876), $A$ Classification and Subject Index for Cataloguing and Arranging the Books and Pamphlets, (Hartford Connecticut: Case, Lockwood \& Brainard). See also Melvil Dewey (2015 [1876]),

“Melvil Dewey's

Bibliographic Decimal System and its Proposed Application for the Arrangement and Rapid Search of Scientific Subjects Contained in Beejournals," (London: Blackwell Palala Press).

20 Cf Hans G. Schulte-Albert (1971), Gottfried Wilhelm Leibniz and Library Classification, in: The Journal of Library History, Vol. 6, No. 2 (Apr., 1971), 133-152.

21 Alex Wright (2014), Cataloging the World: Paul Otlet and the Birth of the Information Age, (Oxford:

Oxford University Press), 41. 
The implementation of the DDC came with a high initial investment since the library stock had to be reordered according to Dewey's standardised system of categories. Once rearranged according to these criteria, however, the library functioned like a well-organised warehouse of knowledge.

The rigid DDC system originally featured nine main 'classes', which were divided again into nine divisions. A final division was then made by separating each subset into nine sections, also numbered with the nine digits. In this way, a high number of increasingly differentiated categories could be created-all identified with a three-digit code or a 'call number' which indicated both the book's subject and its exact location. In addition to the listing of the general classes and their subsets, Dewey also provided a separate subject table and an index of authors that also pointed towards the matching coordinates within the DDC matrix.

Even Dewey's very first concept dating from 1873, set the number zero to indicate-depending on its position in the DDC code-that a book was non-specific in relation to a class, division or section. This addition also became necessary to guarantee the integrity of the three-digit number code. In the first issue of his catalogue all of the zero main categories were, as yet, unassigned placeholders. Today some of these numbers are used for subjects that in the late 19th century did not yet exist: 000 - Computer science, knowledge \& systems, for example.

As efficient as the initial system might have been, it also raised immediate and serious questions, some of which haunt us today. The first one relates to the limited and predetermined set of main categories themselves. Since the DDC was standardised and had a monopoly position from the beginning, it was biased towards an Anglo-American worldview, mirroring the values and moral standards of Western culture. As a result it has been very difficult, if not impossible, to change a category once it has been introduced-a fact, which, over time, has produced unwanted distortions, artefacts and some dead-ends. Finally, and most important, the DDC is not able to deal with ambiguity or plurality. Its core was designed to subdivide knowledge into a strict set of limited vertical hierarchies that raise serious problematic issues on multiple levels. 
The archaic structure and limited adaptability of the DDC and the attempt to eliminate its conceptual flaws (and similar rigid systems such as the Library of Congress Classification introduced in 1890), have been constantly evolving over the last century. The DDC categories have grown from a few hundred to some 36,000 today and, with later extensions adding further subdivisions, it is now hypothetically possible to envisage up to one-billion classifications. On first sight this increase in granularity seems to characterize an open system capable of integrating any number of new data-but unfortunately this is not the case. This is because information based on paradigm changing new knowledges can only be added at deeper levels in the hierarchy and, therefore, it leaves the pre-existing order substantially unaltered. It is also worth noting that Leibniz's vision of the mechanisation of knowledge could never actually be applied to this kind of cataloguing system, because the predetermined position of a book and its attributed class does not add any useful information, other than making it physically traceable and showing its contiguous fields. Leibniz's quest for a universal particle achieved by endless division, subdividing knowledge into ever finer classes ultimately leads to the most individualised element of all: a useless category represented by a single entry.

\section{The quest for universality}

Next to his classification system, Dewey also commercialised another important instrument that was not of his own invention: the card index catalogue. It has been asserted that Swedish botanist, zoologist and physician, Carl von Linné, first used a similar ordering system around 1760 so as to keep his lifelong attempts to classify all known species as flexible as possible. On an institutional level the first card catalogue was installed around 1780 at the Austrian court library in Vienna by its prefect, Gottfried van Swieten. However, it was Paul Otlet who brought these two innovations together and developed a modern system for organising information that was both universal and flexible enough to map the diversity of human knowledge. Otlet, offspring of a wealthy Belgian family and a trained lawyer, began to take an interest in bibliography during his studies and eventually developed doubts as to the usefullness of the book and with it the library as general guardians of knowledge.

\footnotetext{
alignment [ə'lainmənt]

something meeting point-for-point with its other. in a modernist world, this requires an agreement. in a postmodernist world, it requires only a pluralised encounter that for whatever reasons 'cohere'.
} 
22 Paul Otlet, (1990 [1891-92]), “Un peu de bibliographie (Something about Bibliography)," in W. B. Ray (Ed.), The International organisation and dissemination of knowledge: Selected Essays of Paul Otlet, (Amsterdam: Elsevier), 11-24.

23 Scott Hamilton Dewey (2014), "The Continuing Relevance of Paul Otlet, the International Institute of Bibliography/ International Federation for Documentation, and the Documentation Movement for Information Science and Studies," in InterActions: UCLA Journal of Education and Information Studies, 10(2), at escholarship.org/uc/ item/5pq3v1cp

24 Alex Wright, Cataloging the World, 82-83.
In his first essay in 1892, Otlet expressed the belief that books were an inadequate way to store information because they were hard to update and based more on the author's own biases than on checkable facts. ${ }^{22}$ In his opinion, a far more effective approach would be to distil a book's substance, its sources and conclusions and connect all elements using a system of cards pointing to distinct units of information or-as he would later call it-documentation. ${ }^{23}$ In 1895 he and his life-long associate and future Nobel Prize winner, Henri La Fontaine, established the International Institute of Bibliography in Brussels and announced plans to create a Universal Bibliographic Repertory that would serve as a global clearinghouse for bibliographical data. ${ }^{24}$ It was the initial intention to create a comprehensive classified index of all published information worldwide. As part of their research, Otlet and La Fontaine learned about the Dewey Decimal Classification, which they wished to adapt for their own purposes. ${ }^{25}$ After obtaining permission to translate the DDC into French, they immediately started to deconstruct and rebuild it in a most ingenious and surprising way.

Fig. 4: Card Division at the Library of Congress.

Photograph by Underwood \& Underwood around 1919

(Library of Congress)

25 Ibid, 165. 
Having grasped the fundamental restrictions of Dewey's original concept, they overcame the purely enumerative classification, transforming it into one that allowed for synthesis and crossconnection. By 1905 the system had been further refined by introducing interlinking and aspect-free tables containing general notions such as place, language and physical form. In addition, a system of algebraic notation and syntax rules was introduced that referred to the intersection of connected subjects. In creating an inquiry-oriented stock of knowledge that was structured and described by means of a proper documental language, the UDC was able to express an unlimited combination of attributes and relationships per subject. With its highly elaborated subject arrays, its auxiliary tables and a number of compounding mechanisms, the Repertory was designed to enable the creation of systematically

26 Rayward W. Boyd (2013), 14-17 structured number codes that could specify in minute detail extremely complex statements of what a document was about. The algebraic notation for such a formalisation would for example read $31:[622+669](485)$ referring to the statistics of mining and metallurgy in Sweden.

Otlet's and La Fontaine's thinking was also ground-breaking for another reason. They radically questioned the unchallenged authority of books by proposing that the narrow limits of text-based information should be expanded to include the spoken word, artefacts, maps, photographs and all other kinds and mediums of expression. In order to include this expanded scope of relevant sources they introduced the concept of what they called the 'Universal Book' and, with it, the new discipline of documentation sciences. These sciences are characterised today as the study of the recording and retrieval of information. ${ }^{26} \mathrm{As}$ unimpressive as these proposals may seem, their consequences were far-reaching and soon went well beyond the scope of library science. They raised the general question about which kind of information should be considered relevant and valuable enough to be stored and integrated. This immediately led to the next issue as to how human knowledge should actually be described, stored and distributed. Since then these questions have retained their profound relevance up to and including the present day. 
27 Cf Universal Bibliographic Repertory at archives.mundaneum.org/en/ universal-bibliographic-repertory

28 Paul Otlet (1906), "Les aspects du livre: conférence inaugurale de l'expostion du livre belge d'art et de litTérature organisée à Ostende par le Musée du Livre," in Publication No. 8 (Bruxelles: Musée du Livre), 34. schmidt and Paul Otlet, Paul (1906). "Sur une forme nouvelle du livre: le livre microphotographique," in Publication No. 81, (Bruxelles: Institut international de bibliographie).

\section{A radiant library}

Following Otlet's concept, all relevant information was collected worldwide and processed in his central repository, the Palais Mondial (World Palace) founded in Brussels in 1910 with the help of the Belgium government. There, each source had to first be identified, then documented on $3 \times 5$ inch index cards and interlinked according to the UDC. This tedious decision making and classification process was manually performed by anonymous experts-mainly women, as one can see in historical photographs-under Otlet's direction and supervision. Their role was fundamentally different from the librarians of the past since they were no longer keepers of the knowledge, but also readers, indexers, coordinators, abstractors, summary writers and, therefore, ultimately synthesizers.

In this way Otlet's catalogue developed into a remarkable resource, which, in the period before World War I, grew to more than 11 million index cards and peaked in 1934 at 15.6 million. ${ }^{27}$ His visionary aim however was not to silo or monopolize knowledge, but to make it accessible so as to democratise the dissemination of culture and information. An ardent pacifist, Otlet was convinced that long-term world peace would be supported by an international and unbiased knowledge base open to everyone. One of the main obstacles to this knowledge exchange was, however, the fact that at the time there was no simple way to duplicate and transmit the physical records generated and archived in the Palais Mondial. In order to overcome this problem Otlet was constantly looking for new technical solutions and was enthusiastic about every new invention that seemed to bring him closer to his goal. As early as 1906 he claimed that the book of the future would be "the photographed book, the telephoned book, the projected book, [...and] the Broadcast Book". ${ }^{28}$ That same year Otlet began collaborating with Belgian chemist and radio pioneer Robert Goldschmidt to explore the possibilities of microfilm as a new archival storage medium. In their 1906 Essai sur une forme nouvelle du Livre: Le Livre Microphotographique, Goldschmidt and Otlet argued that an inflammable sheet film the size of an index card could contain the contents of 72 book pages and would not be limited to text information alone, but capable of reproducing any kind of pictorial content. ${ }^{29}$

ambiguous [æm'brgjuəs]

conviction destabilised by choice. 
Although the technical realisation of a miniaturised and reproducible library could not be achieved at the time, the concept already incorporated an interesting idea that would eventually be put into practice in the late 1920s. One of these implementations, not directly connected to Otlet's visionary work, merged a lot of his ideas and, to some extent, exceeded them.

The Statistical Machine was initiated and constructed by Emanuel Goldberg of Zeiss Ikon in 1927 and can be considered the first document retrieval system using electronics. ${ }^{30}$ The function of the machine was surprisingly sophisticated for its time: microfilm records were stored as single images on rolls of $35 \mathrm{~mm}$ cine film and each record was indexed with a binary code in the form of a specific black and white pattern. A technical solution, this was basically a further development of the mechanism used in punch card sorting machines since the 1900's and is echoed in the QR codes of today. ${ }^{31}$ By using microfilm in this way, one could then create a search key featuring a similar black and white pattern enabling the retrieval of documents based on certain defined criteria. During the search process the film ran at high speed between a light source and a photocell and once it passed a frame with an identical code, it stopped. This target detection instantly triggered a second process in which a copy of the found record was printed onto a separate piece of film. The result of such a query was a newly composed microfilm containing all results in the sequence they had occurred.
30

Buckland (2006),

Emanuel Goldberg

and His Knowledge

Machine: Informa-

tion, Invention, and

Political Forces,

(London: Libraries

Unlimited).

31 The first elec-

tromechanical

punch card sorters

and tabulating

machines were

introduced around

1900 by the Ameri-

can Hollerith Com-

pany, which later

was amalgamated

with three other

companies to form

the International

Business Machines

Corporation (IBM).

The Hollerith

machine allowed

the evaluation of

a large number of

punched cards in a

short time and was

therefore often

used for national

censuses. In order

to process digital

data, it had to be

presented in the

form of standard-

ised punch cards

with holes in pre-

defined positions.

Unlike punched

cards, the printed

pattern is scanned

by optical sensors.
Fig. 5: L'univers, l'intelligence, la science, le livre. Illustration by Paul Otlet published in Traité de documentation, 1934. Insight from the universe and the human mind is according to Otlet ordered by dividing knowledge into scientific grids and materialised into a book. Each fact and each idea kept in every book is isolated and converted into an individual document that is inventoried in a card catalogue. From this catalogue dossiers and maps are made condensing and objectifying the retrieved information. This collected and generated knowledge forms the basis for the constantly growing and increasingly differentiated classification system.

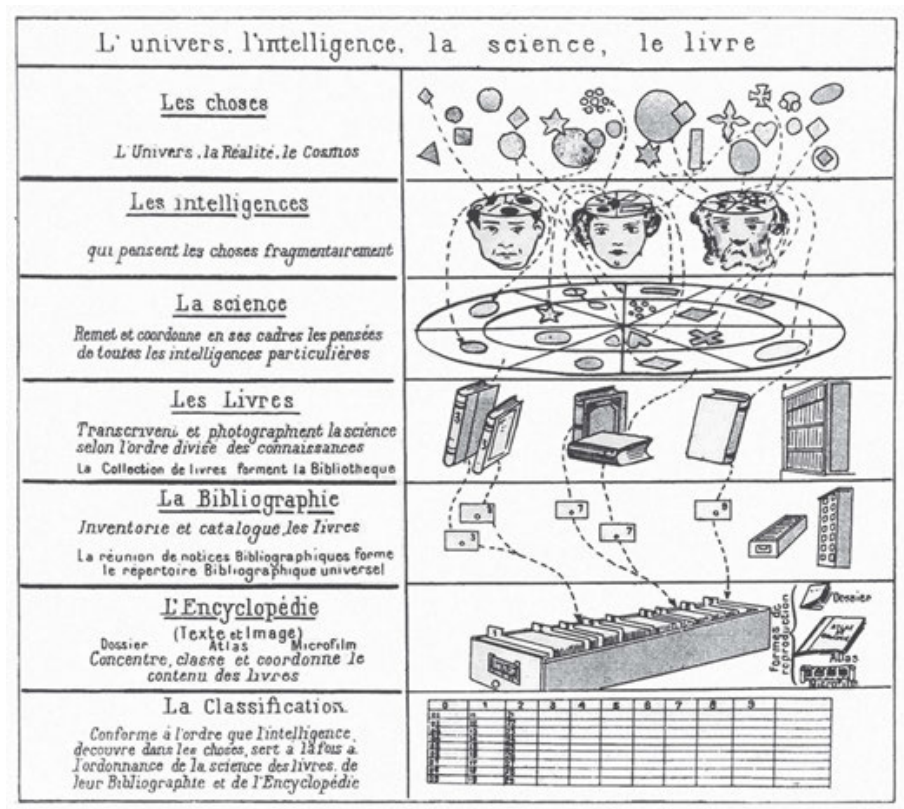


32 Cf Frank Hartmann (2012), Vom Buch zur Datenbank: Paul Otlets Utopie der Wissensvisualisierung, (Berlin: Avinus). See also Alex Wright (2014).

33 "World Brain" in this context refers to a collection of essays by H.G. Wells, dating from the period of 1936 -1938 with which Otlet fas familiar. Throughout the book, Wells describes his vision of a synthetic, authoritative and permanent "World Encyclopaedia" that could help world citizens make the best use of universal information resources thus contributing to world peace. See H.G. Wells (2016 [1957]), World Brain, (London: HG Wells Library Press).

34 Paul Otlet (1934), Traité de documentation: le livre sur le livre, (Brussels: Editiones Mundaneum), Paul Otlet (1935), Monde, essai d'universalisme: connaissance du monde, sentiment du monde, action organisée et plan du monde, (Brussels: Editiones Mundaneum).

35 Paul Otlet, Traité de documentation, 429.
One reason for mentioning this long forgotten technical solution lies in the ingenious idea of skipping the level of index cards and automating the search in a way that the document as such is presented. The retrieval process for its part is driven by a machine readable and highly formalised descriptor such as the one used in the UDC. Although Emanuel Goldberg had to leave Nazi Germany in the early 1930s and for this reason his Statistical Machine never went into production, it would have been an intriguing possibility of realising and enriching Otlet's vision. The important point here is that even in an analog society a machine existed that could construct a search engine easily recognised today. This puts a different perspective on the idea that the use of computers automatically led to a qualitative advance in the complexity of knowledge systems. That was not the case, at least until very recently.

After a long time in oblivion, Paul Otlet is now seen as a pioneer of information sciences and the Internet. ${ }^{32}$ Nevertheless, references nowadays are made mainly to his later publications and not to the previous decades of hard work on his vision of the "World Brain." ${ }^{33}$ In his recently rediscovered and not yet translated works from the mid-1930s, Traité de documentation and Monde: essai d'universalisme, he did not only summarize a lifetime of thought about the organisation of knowledge, but also interpolated some of his utopian ideas, through which we recognize the world of today. ${ }^{34}$ In his Traité de documentation, for example, Otlet predicted that future instruments would automatically capture data without direct human intervention and that these instruments would also be able to detect all sensebased perception and even qualities beyond them. He further suggested that there would be mechanisms corresponding to each form of peception, ultimately leading towards a shift whereby all reality would be recorded in a process he called

Hyper-Documentation. ${ }^{35}$

Fig. 6: Laboratorium Mundaneum. Ink drawing by Paul Otlet, 1940 (Collections Mundaneum). Yet another way of gathering knowledge according to Paul Otlet: all kinds of information, from different sources, is transported by cable cars to an industrial complex where it is collected and processed in an enormous furnace. The product of this intellectual mining operation is the UDC code. The text below explains that mountains of documents extract the pure materials useful to civilisation. 


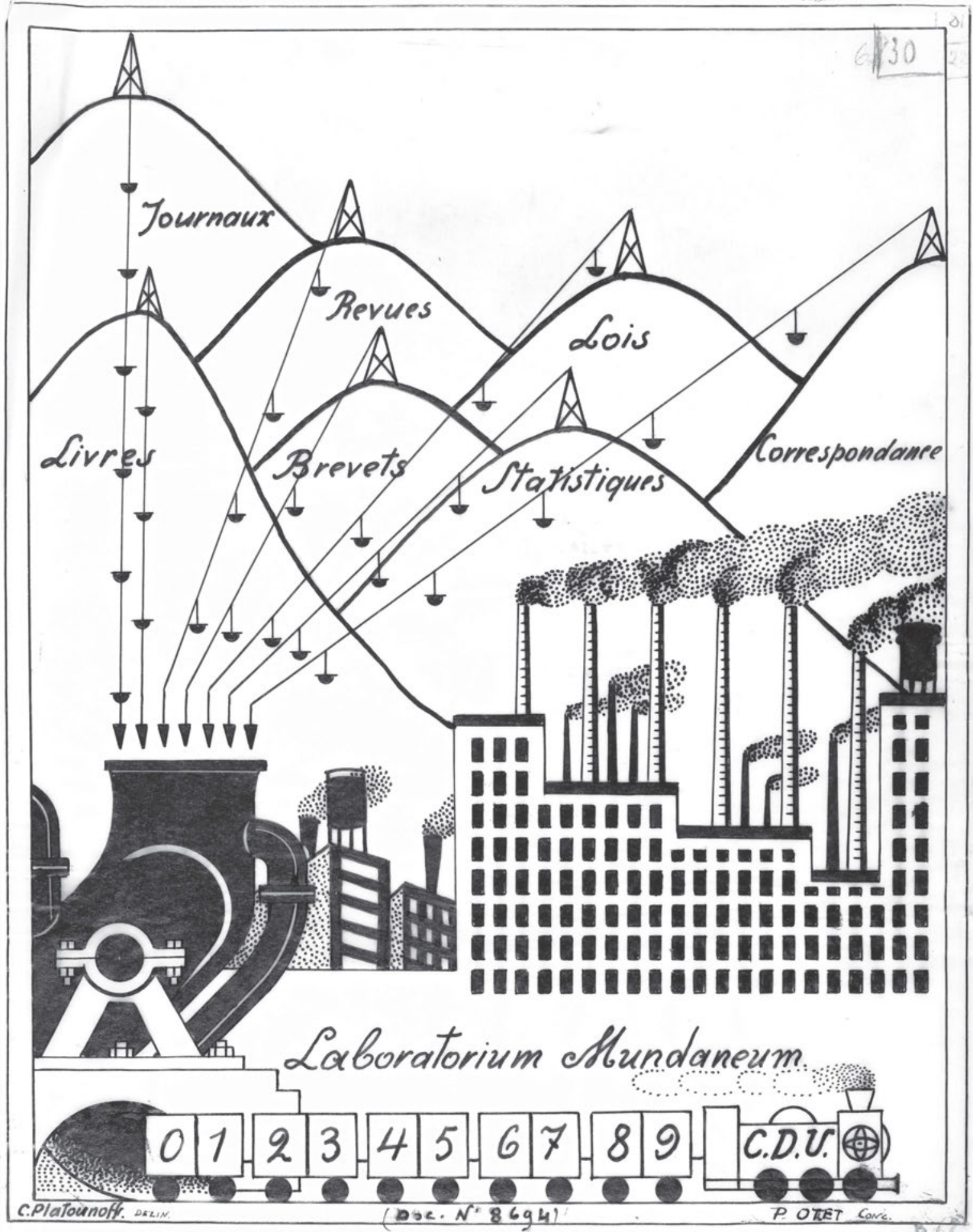

La CENTRALE DE DOCUMENTATION II DES MONTAGMES DE DOCUMENTS EXTRALRE

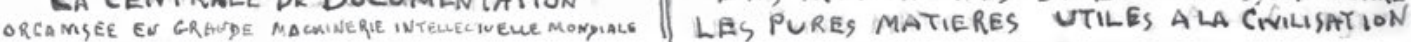




\section{Future as past participle}

At this precise point I would like to return to some thoughts laid out at the beginning of this text; namely, the paradisiacal conception of God's own language in which there is no difference between the descriptor and its referent. Very recently we have entered a new phase in data retrieval and modelling whereby, with the aid of neural machine learning and increasing sensory networking, we materialize an 'internet of things' that for the first time automatically and continuously generates data. In this way the relations between the world and the model of the world are shaped according this continous generating of data. Machine-generated data is produced in such volume and speed that conventional modelling and classification techniques are bound to fail. Instead 'artificial intelligence' is used to transform this permanent flow of input into books and libraries as self-describing data formats which, on the fly and in real time, themselves dictate the underlying multi-dimensional models. From a dystopian point of view, this process can be regarded as the ultimate loss of control or the final surrender of humanity to machines. This is a view that I do not share. Instead it merely indicates that once again have reached a crucial point of epochal paradigm shift. With the help of these new technologies, knowledge and all forms of human expression finally can be recorded, correlated and understood in the universal sense that Otlet proposed in his late writings. Very clearly he came to the conceptual point where the distinction between the meaningful and the coincidental started to blur and the only consequence he saw was to integrate everything that could be described and captured. After a lifetime of trying to bring order to the diversity and unpredictability of life, it must have dawned on him, that knowledge systems by their very nature do not have to be instrumentalised or closed. There can never be a strong curator or moderator-or not for long anyway-if knowledge is going to wear garments that flow, multiply, proliferate, whilst simultaneously bolstering or even foregrounding curiosity.

\footnotetext{
animal ['æniməl]
}

In the grip of the

anthropocene, it is crucial to re-remember that the universe does not revolve around (a) earth and (b) the human species. sentient beings with or without backbones, often without humanly discernable communication systems, are sometimes so odd that they can appear as aliens from another planet / deep time zones. see also cephalopods, paying close attention to their armpit-mouth-genitals and wry sense of wonderment, play, cruelty and humour. 
The final consequence of this wilful overflow carries a strong spark of openness within it, which leaves no space for narrow ideological or moral judgement and is irreducible to instrumental logic. Instead it allows a complex and ambiguous mesh of diverse information to emerge. In contrast to the pure knowledge of the enlightenment, these future systems are infinitely impure, compounded as it is by ever proliferating data, whilst simultaneously cohering as a living distribution. It is certainly not a given that such utopian and shape-shifting systems would make humans 'God-like'-but they would name everything, expressing it within an inherently limited and fluctuating web of intersecting data.

This is precisely what the Data Loam project has been about: the encounter of meaning formation and the fight for the right to keep encounters 'flowing'. Data Loam foregrounds diversity and shows precisely how to make that diversity 'work'. Hopefully this will help to form the basis of a new democratic intelligence. 